\title{
GnRHa Treatment of Cryptorchid Boys Affects Genes Involved in Hormonal Control of the HPG Axis and Fertility
}

\author{
Faruk Hadziselimovic $^{\mathrm{a}}$ Katharina Gegenschatz-Schmid ${ }^{\mathrm{a}}$ Gilvydas Verkauskas ${ }^{\mathrm{b}}$ \\ Philippe Demougin $^{d}$ Vytautas Bilius $^{b}$ Darius Dasevicius ${ }^{c}$ Michael B. Stadler ${ }^{e}{ }^{f}$ \\ ${ }^{a}$ Cryptorchidism Research Institute, Kindermedizinisches Zentrum Liestal, Liestal, Switzerland; ${ }^{\mathrm{b} C h i l d r e n ' s ~ S u r g e r y}$ \\ Center, Faculty of Medicine, University of Vilnius, and 'Institute for Pathology, National Center of Pathology, Affiliate \\ of Vilnius University Hospital Santariskiu Klinikos, Vilnius, Lithuania; ${ }^{d}$ Biozentrum, Life Sciences Training Facility, \\ University of Basel, ${ }^{e}$ Friedrich Miescher Institute for Biomedical Research, and f Swiss Institute of Bioinformatics, \\ Basel, Switzerland
}

\section{Keywords}

Cryptorchidism · GnRHa treatment · Infertility ·

RNA sequencing

\begin{abstract}
The gonadotropin-releasing hormone agonist ( $\mathrm{GnRHa}$; Buserelin) rescues fertility during adulthood in the majority of high infertility risk cryptorchid boys presenting with defective mini-puberty. However, the molecular events governing this effect are not understood. We report the outcome of an RNA profiling analysis of testicular biopsies from 4 operated patients who were treated with GnRHa for 6 months versus 3 operated controls who were not treated. GnRHa induces a significant transcriptional response, including proteincoding genes involved in pituitary development, the hypothalamic-pituitary-gonadal axis, and testosterone synthesis. Furthermore, we observed an increased abundance of long noncoding RNAs (IncRNAs) participating in epigenetic processes, including AIRN, FENDRR, XIST, and HOTAIR. These data
\end{abstract}

are consistent with the hypothesis that hypogonadotropic hypogonadism in boys with altered mini-puberty is the consequence of a profoundly altered gene expression program involving protein-coding genes and IncRNAs. Our results point to molecular mechanisms that underlie the ability of GnRHa to rescue fertility.

(C) 2017 The Author(s)

Published by S. Karger AG, Basel

Early treatment of cryptorchidism to improve fertility is the recommended course of action [Ritzén et al., 2007; Kolon et al., 2014]. However, not all cryptorchid boys will develop into fertile adults in spite of timely corrective surgery [Hadziselimovic and Herzog, 2001]. At the molecular level, numerous differences in gene expression between high infertility risk (HIR) and low infertility risk (LIR) groups were observed, which underscores the importance of an intact hypothalamic-pituitary-gonadal (HPG) axis for the development of normal adult spermatogenesis [Hadziselimovic et al., 2009,

Prof. Dr. med. Faruk Hadziselimovic

Kindermedizinisches Zentrum

Bahnhofplatz 11

CH-4410 Liestal (Switzerland)

E-Mail info@kindermedizin-zentrum.ch 
2011; Chalmel et al., 2012]. These data strongly support the theory that in HIR cryptorchid boys, insufficient PROK2, CHD7, FGFR1, and SPRY4 gene expression induces deficient LH secretion, which results in impaired mini-puberty and ultimately in adult infertility [Hadziselimovic et al., 2016]. In male infants, gonadotropin secretion increases between 2 and 4 months after birth, which stimulates Leydig cells to secrete testosterone [Forest et al., 1974; Winter et al., 1976]. This testosterone increase is blunted in cryptorchid infants [Gendrel et al., 1978], which results in an inadequate transition of gonocytes into A dark (Ad) spermatogonia [Bica and Hadziselimovic, 1992; Zivkovic et al., 2007]. Consequently, establishing adult fertility following successful surgery is largely dependent on a normal mini-puberty and, as a result, the presence of Ad spermatogonia in the testis [Hadziselimovic et al., 2005; Hadziselimovic and Hoecht, 2008]. In a prospective study, it was found that $47 \%$ of cryptorchid patients undergoing surgery lacked Ad spermatogonia in their testis and where thus highly likely to become infertile as adults [Bilius et al., 2015]. In 1997, cryptorchid boys of at least 8 years of age, who were treated with gonadotropin-releasing hormone agonist (GnRHa; Buserelin), showed improved sperm concentrations when compared to an untreated control group [Hadziselimovic and Herzog, 1997]. GnRHa treatment on alternate days over a period of 6 months did not inhibit gonadotropin secretion, while levels of LH increased and atrophic juvenile Leydig cells regenerated towards the end of the treatment [Hadziselimovic et al., 1984]. Thus, the treatment increased the number of germ and Leydig cells [Hadziselimovic et al., 1984, 1987]. Importantly, long term follow-up in HIR cryptorchid boys treated before the age of 6 showed normal sperm concentrations for $86 \%$ of the cases [Hadziselimovic, 2008].

This result showed for the first time that infertility resulting from undescended testis, which was believed to be an incurable congenital malformation, could be prevented. However, little is known about the molecular mechanisms governing this phenomenon, and no large-scale expression data are available on the short-term effects elicited by a 6-month hormonal treatment for HIR patients as compared to surgery alone. This study presents RNA profiling data that reveal the transcriptional effects elicited by GnRHa treatment. Critically, we identified genes that regulate the pituitary testicular axis development in both the canonical and alternate pathways, as well as long noncoding RNAs (lncRNAs), including some that are involved in epigenetic processes.

GnRHa Affects Genes Involved in Fertility

\section{Subjects and Methods}

Study Population and Biopsy Sample Collection

Seven bilateral cryptorchid boys with a median age of 18.5 months (range 8-59 months), who had received no hormonal or surgical treatment prior to randomization, were selected. Data from patients treated either with surgery and $\mathrm{GnRHa}$ (4 patients) or with surgery alone ( 3 patients) were retrieved from an ongoing randomized study for further analysis. We included 14 biopsies of 7 patients before and after the treatment. Initial biopsies revealed no Ad spermatogonia, indicating a defective mini-puberty. The second testis of all patients was orchidopexied and biopsied 6 months after their initial surgery. In addition, RNA sequencing data from our previous study (7 HIR and 8 LIR patients) were included [Hadziselimovic et al., 2016]. Thus, altogether results from 22 patients were compared. Boys in the GnRHa-treated group received $10 \mu \mathrm{g} \mathrm{GnRHa}$ (Buserelin), administered as a nasal spray, in the evening of every second day over a period of 6 months. A cryptorchid testis is defined as a testis localized outside of the scrotum and incapable of being brought into a stable scrotal position. All undescended testes in this study were located in the inguinal region. The cryptorchid boys entering the study underwent an extensive examination with no clinical signs of developmental malformations or syndromes. Performing clinical examination in accordance with STROBE criteria for case-controlled studies [von Elm et al., 2014], we excluded patients with small testes, a small penis, or a lack of normal scrotal rugae, pigmentation, and gynecomastia. We further determined serum FSH, LH, testosterone, and inhibin levels [Verkauskas et al., 2016]. No MRI scans of the brain and sella turcica were performed. No clinical symptoms were found for hyperprolactinemia, pituitary lesions (tumor, granuloma, and abscess), Cushing syndrome, severe or chronic illness, trauma or surgery, or genetic mutations such as Prader-Willi syndrome. None of our patients suffered from a systemic disease such as hemochromatosis, sarcoidosis, or histiocytosis X. Testicular biopsies were taken at the time of orchidopexy. A 5-mm incision was made into the tunica albuginea in the superior pole of the testis, and a sample of approximately the size of a rice grain was isolated from the protruding tissue using separate blades. This sample was then subdivided, with one fragment fixed in glutaraldehyde for histological processing, while the other one was immediately immersed in RNAlater (ThermoFisher Scientific) and stored at $-25^{\circ} \mathrm{C}$ until further processing (for RNA extraction and RNA sequencing).

\section{Histological Analyses}

Biopsies were fixed in 3\% glutaraldehyde in PBS and then embedded in Epon resin. Semi-thin sections $(1 \mu \mathrm{m})$ were cut using a Reichert Om-U3 ultramicrotome. Sections were mounted on glass slides, stained with $1 \%$ toluidine blue, and examined under a light microscope at a total magnification of $\times 600$. Biopsies were histologically examined by 2 of the authors (FH and DD), each with expertise in the interpretation of semi-thin sections of prepubertal testes.

During histological analyses, at least 100 tubular cross sections per biopsy were evaluated with regard to their number and absence of Ad spermatogonia. In the prepubertal testis, Ad spermatogonia were identified according to the criteria first published by Seguchi and Hadziselimovic [1974]. This type of germ cell has a typical halo in the nucleus, termed the rarefication zone, and a cytoplasm with

Sex Dev 2017;11:126-136 


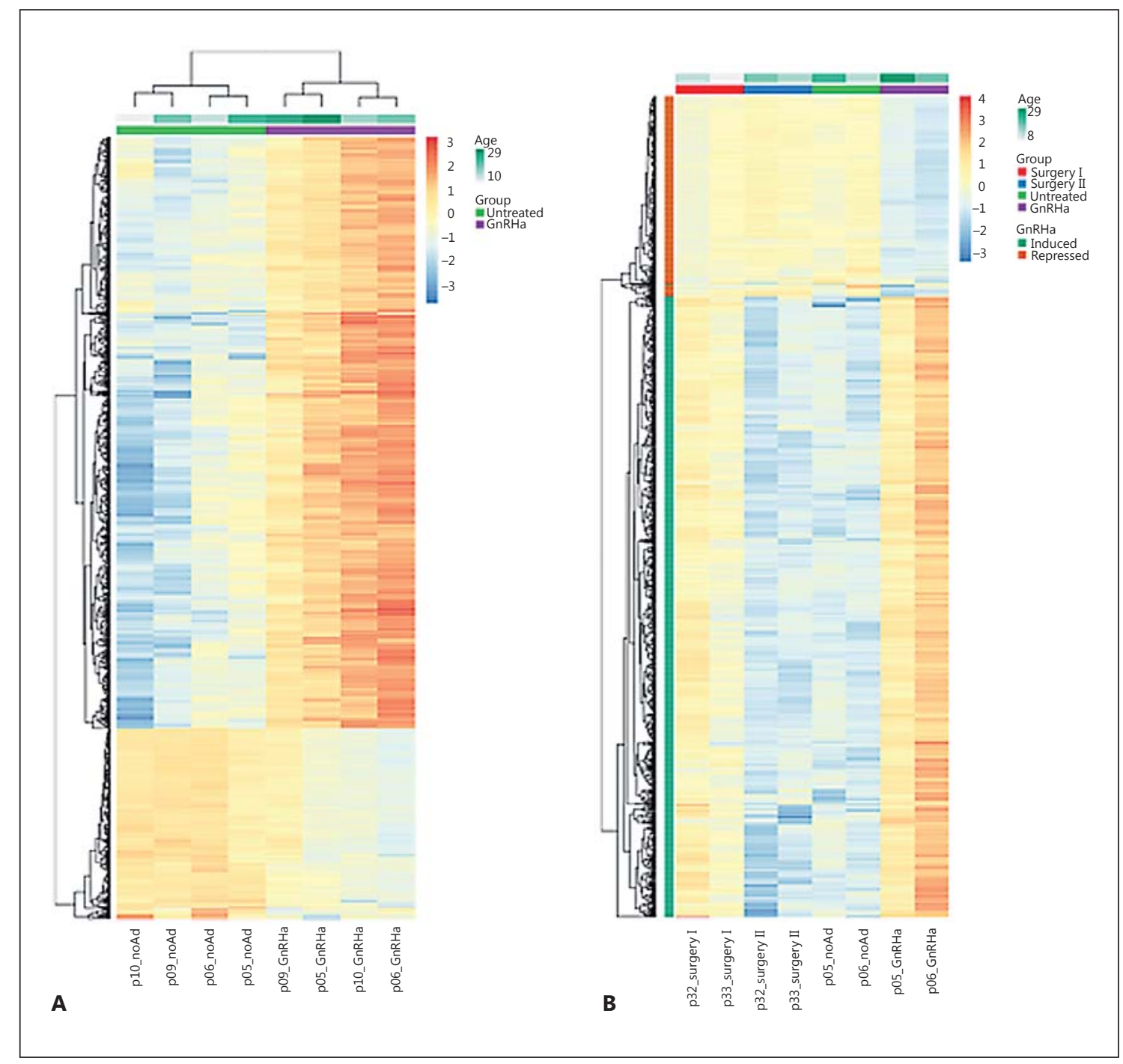

Fig. 1. Heatmap of differential expressed genes showing the log2 expression of the 1,000 most significant differential genes between before/after GnRHa treatment $(\mathbf{A})$ and between surgery-only and GnRHa-treated patient groups (B). Patient group and age are color-coded and indicated on the top and on the right side of each heatmap. Genes have been reordered by hierarchical clustering to group similar profiles (clustering dendrograms shown on the left side).

a darker aspect in comparison to Ap or fetal spermatogonia. Crucially, the predominant factor in the development of infertility is the observation that gonadotropin levels show a more striking correlation with the presence or absence of Ad spermatogonia in both gonads than with the category of undescended testes, i.e., unilateral or bilateral [Hadziselimovic and Hoecht., 2008].

\section{RNA Preparation, Sequencing, Data Analyses, and RNA}

\section{Expression Levels}

The workflow from RNA isolation to purification, library preparation, sequencing, data analyses, and expression level analysis has been described previously (HIR/LIR differential gene expression study) [Hadziselimovic et al., 2016]. These steps were per- formed in parallel in an identical fashion for the GnRHa-treated and surgery-only groups.

\section{Data and Differential Gene Expression Analyses}

To determine genes differentially expressed before and after GnRHa treatment, the counts per gene sample from patients treated with GnRHa were statistically analyzed in R using the edgeR package [Robinson et al., 2010] by fitting a quasi-likelihood negative binomial generalized log-linear model for each gene [Lund et al., 2012]. The model was designed with 2 additive categorical factors: (1) patient, which identifies measurements from the same patient, before and after GnRHa treatment, and controls for gene expression differences between individuals, and (2) treat- 
ment, which models gene expression changes induced by GnRHa. Only genes with at least 1 read per million in at least 2 samples were included. $p$ values and fold changes were calculated for the treatment factor, and differentially expressed genes were defined as those displaying a false discovery rate (FDR) of $<0.05$ and an absolute change in expression of at least 2 -fold. FDR-controlling procedures are designed to estimate the expected proportion of "discoveries" (rejected null hypotheses) that are false (incorrect rejections) and is one way of conceptualizing the rate of type I errors in null hypothesis testing when conducting multiple comparisons. FDR-controlling procedures provide less stringent control of type I errors compared to familywise error rate (FWER) controlling procedures (such as the Bonferroni correction), which control the probability of at least one type I error. Thus, FDRcontrolling procedures have greater power at the cost of increased rates of type I errors. Cut-off was not applied to raw $p$ values, but significant values of $<0.05$ were corrected for multiple testing; namely FDR was calculated after the Benjamini and Hochberg [1995] approach.

Protein Interaction Network

Genes involved in the HPG axis, pituitary and neuronal development, and differentially expressed in the HIR versus LIR group, together with the genes differentially expressed in the GnRHatreated versus untreated group (146 genes in total) were used as inputs to obtain the protein-protein interaction network using STRING version 10.0 [Szklarczyk et al., 2015].

\section{Results}

\section{GnRHa Treatment but Not Surgery Alone Affects}

Gene Expression

RNA profiling of samples from 4 patients before and after GnRHa treatment detected 28,645 transcripts. Of these, 6,469 showed a significant difference in concentration levels, whereby an increased expression was observed for 5,823 cases (90\%) following GnRHa treatment (FDR $<0.05$; absolute expression change $\geq 2$-fold). Distinct gene expression profiles before and after GnRHa treatment were identified and are summarized in Figure 1A (online suppl. Table 1; for all online suppl. material see www. karger.com/doi/10.1159/000471937).

Next, we asked whether a transcriptional response was triggered in patients who had undergone only orchidopexy without GnRHa treatment. A differential expression analysis that included paired samples from patients before/after surgery and with/without GnRHa treatment indicated that only very few significant effects were elicited at the transcriptional level following solely surgical intervention (Fig. 1B, compare lanes $1 / 3$ and $2 / 4$ ). This finding is in agreement with the common pathology found in biopsies from both testes and confirms previous observations that both testes in bilateral cryptorchidism

GnRHa Affects Genes Involved in Fertility have the same abnormal testicular histology and low numbers of spermatogonia [Hedinger, 1979].

GnRHa-Responsive Genes Act in Pathways Critical for the Hormonal Control of Sexual Reproduction, Pituitary Development, and Testosterone Synthesis

In our previous study, HIR patients showed a significant reduction of the expression level of genes involved in the HPG axis [Hadziselimovic et al., 2016]. Therefore, we focused on the effects of GnRHa on these genes and found consistent expression patterns, i.e., the expression level was decreased in the HIR group and increased following GnRHa treatment. The GnRHa response includes loci involved in the regulation of gene expression $(D L X 3$, DLX6, DLX6-AS1/Evf-2, EGR2, FOXG1, ISL2, NHLH2, OTX2, PAX7, POU3F2, POU6F2, RGS7, SOX1, and SOX30), chromatin modification (PRDM9), and signal transduction (NOS1) (Fig. 1A; online suppl. Tables 1, 2). FOXG1 was suggested to be involved in GnRH neuron development [Duggan et al., 2008; Garaffo el al., 2015] in a similar fashion to $D L X 3$, which acts as a transcriptional activator for both $G n R H R$ and $\alpha G S U$ [Xie et al., 2013]. GnRHa also increases the expression of ISL2 and OTX2 (online suppl. Table 1). ISL2 is a gene implicated in neural stem cell differentiation and in the derivation of lineage-specific markers. LHX4 is an important paralog of ISL2. OTX2, a homeodomain protein shown to be expressed in murine GnRH neurons, is upregulated during GnRH neuronal development, increases GnRH promoter activity in GnRH-neuronal cell lines, and ensures reproductive competence [Diaczok et al., 2011]. Additionally, NRG1 and NR4A2, 2 genes important in neuronal differentiation and transcriptional regulation [Park et al., 2003], displayed elevated expression following GnRHa treatment (online suppl. Table 1).

Interestingly, a number of transcripts important for pituitary development that were not differentially expressed between the HIR and LIR groups were still upregulated following treatment. They include an lncRNA important for heart and body wall development [Grote et al., 2013], DNA/chromatin binding regulators important for development (DLX1, EGR3, FGF5, LHX4, OTX1, PAX1, PAX2, PAX3, PAX4, PAX6, POU1F1, POU2AF1, POU2F2, POU2F3, POU4F2, PROP1, RUNX2, SOX2), and epigenetic factors involved in histone modification (PRDM12, PRDM16) [Jostes et al., 1990; Walther and Gruss, 1991; Goulding et al., 1993; Dahl et al., 1997; Kioussi et al., 1999] (Fig. 2; online suppl. Table 1). Moreover, GnRHa increased, as expected, the abundance of several genes that regulate testosterone synthesis (HSD3B1, HSD17B2,

Sex Dev 2017;11:126-136 129 


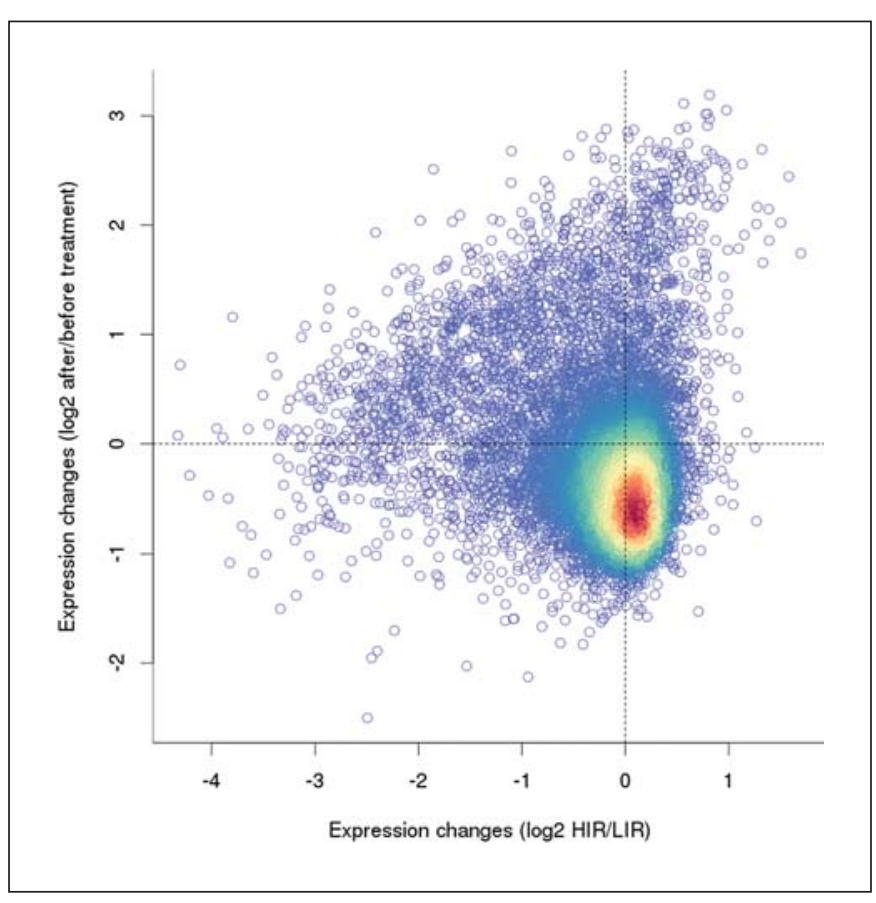

Fig. 2. A plot of the HIR/LIR gene expression changes versus the after/before GnRHa treatment changes. Both HIR/LIR and treatment have specific changes that are unchanged in the other one (genes that are located close to the horizontal or vertical dashed lines), but there are also many genes that are both decreased in HIR and induced by treatment (genes in the upper left of the plot).

CYP19A1, CYP11B2, and CYP11B1) (online suppl. Table 3). GnRHa stimulates LH secretion and the development of juvenile Leydig cells that, secreting testosterone after LH stimulation, display an increased expression of the steroidogenic enzyme HSD3B [Teerds and Huhtanie$\mathrm{mi}, 2015]$. Thus, the observed increase in HSD3B1 expression indicates increased testosterone synthesis. Increased HSD17B2 gene expression yields $17 \beta$-HSD type 2 activity that catalyzes the oxidation of androgens and estrogens equally efficiently, while CYP19A1 encodes the CYP19A1 aromatase, which catalyzes the aromatization of androgens into estrogens. RNA levels for the G-protein coupled receptor class $\mathrm{C}$ group $6 \mathrm{~A}$ (GPRC6A) gene involved in the nonclassical testosterone pathway were also upregulated after GnRHa treatment (online suppl. Table 3). Noticeably, GPRC6A is an amino acid, calcium, and osteocalcin sensing G-protein-coupled receptor that has been reported to mediate the nongenomic effects of androgens [Pi et al., 2010; Pi and Quarles, 2013]. Several genes involved in the androgen receptor pathway also showed increased expression, 2 of which encode kallikrein-related serine peptidases (KLK2 and $K L K 3$ ), with a locus that is extraordinari- ly sensitive to steroids and other hormones involved in androgen receptor signaling. In addition, following treatment, increased levels of RGS7 (regulator of G-protein signaling 7), $A K R 1 B 15$, and $A K R 1 D 1$, were observed (online suppl. Table 3). As a regulator of G-protein-coupled receptor signaling cascades, $R G S 7$ is implicated in the control of hormone release and endocrine functions [Nini et al., 2012]. AKR1B15 is a novel member of the AKR superfamily, and its protein plays a potential role in steroid metabolism, the regulation of mitochondrial function, and aging [Weber et al., 2015]. In the HIR group of cryptorchid testes, this gene was underexpressed in comparison to the LIR group (online suppl. Table 3). The AKRD1D1 enzyme efficiently catalyzes the reduction of progesterone, androstenedione, 17-alpha-hydroxyprogesterone, and testosterone to 5-beta-reduced metabolites. Finally, we also found that expressions of several genes involved in testosterone synthesis were downregulated, e.g., CYP17A1, CYP11A1, $C Y P B 5 B$, and $H S D 17 B 4 / B 1 / B 12 / B 11$ (online suppl. Table 3). GnRHa treatment also stimulated the expression of FGF23, which is involved in nonclassical signaling by androgens, with its physiological effects limited to organs that coexpress the FGFR/a-Klotho complexes such as the pituitary gland [Urakawa et al., 2006; Pi and Quarles, 2013].

\section{GnRHa-Dependent Stimulation of HPG Axis Genes}

We found that differential gene expression patterns between HIR/LIR patients and GnRHa-treated/untreated patients are partially similar. In addition, GnRHa treatment appeared to stimulate in many cases alternative pathways or entire sets of gene families or their homologues. For example, the HIR group showed reduced RNA levels compared to LIR for bone morphogenetic proteins BMP6, $B M P 7$, and BMP8A (online suppl. Table 1), but their expression is unaltered by GnRHa. However, we observed a 2- to 4-fold increase in the RNA levels of BMP3, BMP5, and BMP10 following GnRHa treatment. Similar patterns were found for the family of chemokine ligands (CXCL) and receptors (CXCR).

As opposed to that, GnRHa treatment failed to induce any transcriptional changes in CXCL9 and CXCR4 gene expression, both of which were reduced in the HIR compared to the LIR group. Instead, GnRHa treatment increased gene expression for $C X C L 3 / 5 / 6 / 8 / 11 / 13$, as well as for the chemokine receptors CXCR1/2/5/6. In some cases, GnRHa treatment could both boost the expression of certain genes that were found to have a reduced expression in HIR patients and increase the expression of their family members, e.g., for the $D L X$ family members $D L X 1 / 3 / 6$ and $E G R$ family members $E G R 2$ 
and EGR3; furthermore, for ISL2, NR4A2, OTX1, and OTX2, the listed POU class family members, PR domain containing genes, for RUNX1 and RUNX2, SIX2 and SIX3, as well as for LEP, PCSK1, and TAC3, and finally for the SOX family.

\section{GnRHa Treatment Affects lncRNAs}

Known functions of some nuclear lncRNAs are to regulate gene expression and genome stability. We found that, among others, AIRN, DLX6-AS1, FENDRR, ERICH1-AS1, HAGLR, HOTAIR, OTX2-AS1, IGF2BP2$A S 1, S L C 7 A 11-A S 1$, and TSIX displayed an elevated expression following GnRHa treatment (online suppl. Table 2). This is an intriguing preliminary finding that indicates a potentially important role for $\operatorname{lncRNAs}$ in the overall response to GnRHa treatment during pre-pubertal testis development.

Working under the assumption that divergently transcribed genes can be functionally linked [Grote and Herrmann, 2013; Grote et al., 2013], Grote et al. [2013] suggested that Fendrr (Foxf1 adjacent noncoding developmental regulatory RNA) regulates Foxal and other genes via a Polycomb-dependent epigenetic mechanism. FENDRR was the first lncRNA demonstrated to be essential for mammalian embryogenesis [Grote et al., 2013; Dey et al., 2014]. Notably, Fendrr interacts with WDR5 [Grote et al., 2013], which is well known for its presence in the MLL complexes that mediate H3K4 methylation, a mark thought to counteract H3K27me.

XIST inactivation is an early developmental process in mammalian females that transcriptionally silences one of the pair of $\mathrm{X}$ chromosomes, thus providing dosage equivalence between males and females. This process is regulated by several factors, including a region of the $\mathrm{X}$ chromosome called the $\mathrm{X}$ inactivation center (XIC) [Loos et al., 2016]. The TSIX gene expresses a noncoding antisense transcript (XIST Antisense RNA/ TSIX transcript) across the $3^{\prime}$ end of the XIST (X Inactive Specific Transcript) locus. This antisense RNA was shown to be coexpressed with Xist derived solely from the inactive $\mathrm{X}$ chromosome in reporter mouse embryonic stem cells [Loos et al., 2016].

AIRN (antisense of IGF2R non-protein coding RNA) and HOTAIR (HOX transcript antisense RNA) are both involved in histone modifications [Nagano et al., 2008; Gupta et al., 2010]. The Airn macro ncRNA is the master regulator of imprinted expression in the Igf2 receptor (Igfr) imprinted gene cluster, where it silences 3 flanking genes in cis [Stricker et al., 2008]. Airn expression not only induces silencing of flanking mRNA genes but also

GnRHa Affects Genes Involved in Fertility protects the paternal copy of ICE from de novo methylation. HOTAIR, transcribed from within the HOXC gene cluster, was shown to play a repressive role at the HOXD locus by interacting with PRC2 [Zhang et al., 2014]. In addition, HOTAIR also interacts with the histone H3K4me1/2 demethylase LSD1 (KDM1), which removes a histone mark indicative of active chromatin, thus reinforcing the establishment of a repressive chromatin environment on its target loci [Rinn et al., 2007]. Noticeably, HIST3H3 expression was significantly reduced in the HIR group ( $-3.5 \mathrm{log}$, FDR 0.001).

GnRHa treatment also increased the expression of DLX6-AS1 and OTX2-AS1. Dlx6-as1 (Dlx6 antisense 1, also known as Evf1), transcribed from the genomic region between $D l x 5$ and Dlx6, inhibits the remodeling activity of SWI/SNF (Switching/Sucrose Non-Fermenting), a nucleosome remodeling complex, in order to interfere with the upregulation of Dlx5/Dlx6 [Bond et al., 2009]. OTX2AS1 is a natural antisense transcript (NAT) RNA that plays an important role in eye development [Alfano et al., 2005]. OTX2-AS1 displays sequence complementarity to the exon sequences in its corresponding sense gene, OTX2, both in mouse and human. OTX2-AS1 is predominantly expressed in the retina, with a lower level of expression in the brain. NATs are biologically important sources of endo-siRNAs and are essential components of a regulatory network to control the mutagenic burden that arises at the nucleic acid level without direct consequences for protein expression [Werner et al., 2009].

\section{The GnRHa Response Protein Network}

We next interpreted our transcript signatures in the context of physical protein-protein interactions and functional interactions by integrating our data with information available in the literature (STRING interaction network; http://string-db.org). Among the differentially expressed genes identified in our study, 146 encode proteins that correspond to the hypothalamicpituitary-testicular axis and neuronal development. Analyses of the protein-protein interaction network containing these proteins resulted in high confidence interactions scores $(\geq 0.7)$ for PROP1-POU1F1-PITX1LHX4 and ISL1, and DLX1-POU4F2-ISL1-OTX2-PAX6 with FOXG1 (Fig. 3). Furthermore, additional strong high-confidence interactions were predicted for the chemokine cluster, with NMU linked to both PROK2 and GPRC6A, and NOS1 connected to EGR2, GATA2, and GATA3. Moreover, we observed high confidence connections between EGR2 and GATA3, and WNT3, EBF1, OTX1, OTX2, and POU3F.

Sex Dev 2017;11:126-136 DOI: $10.1159 / 000471937$ 


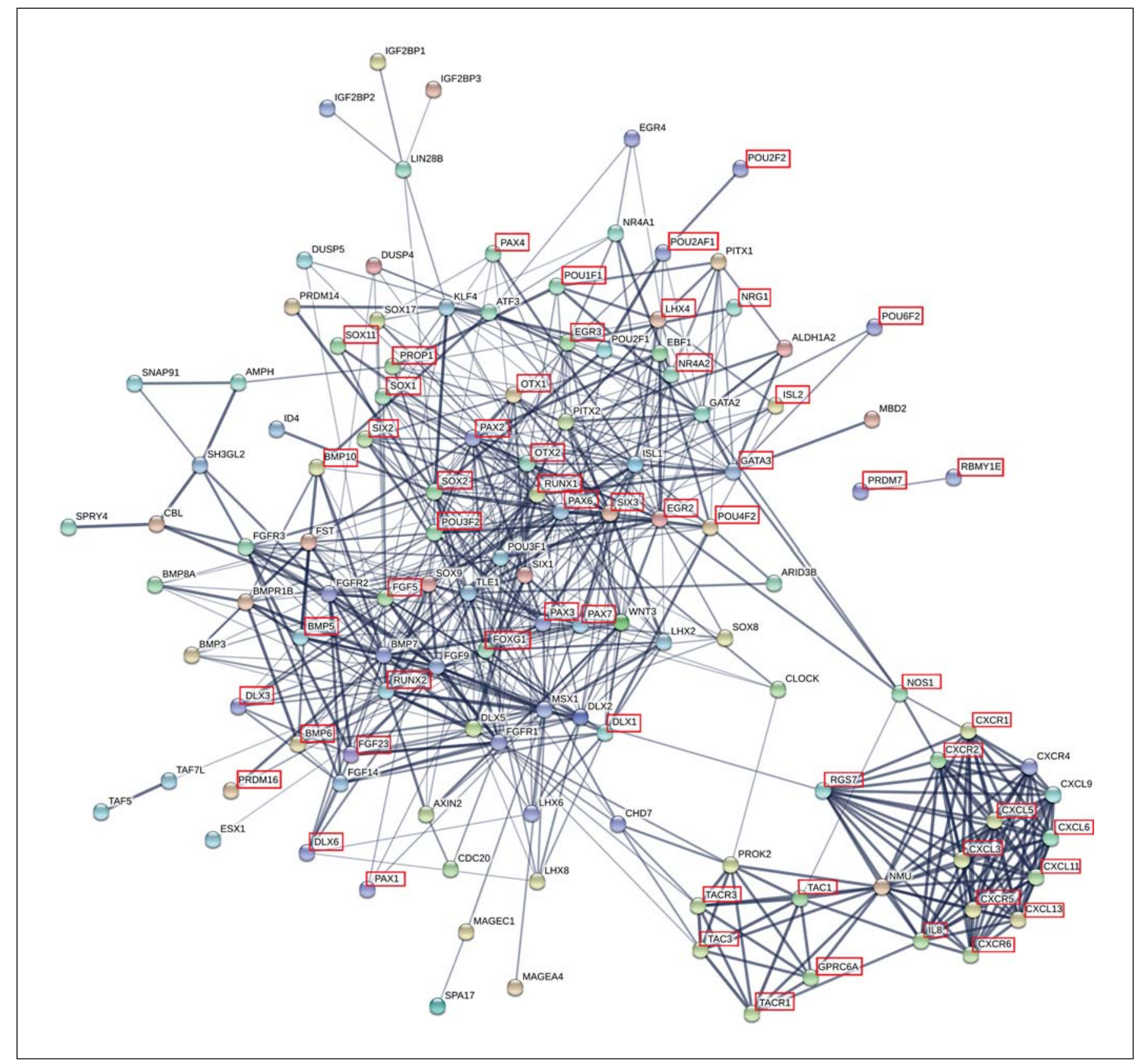

Fig. 3. Protein interaction network of genes involved in the HPG axis and differentially expressed in HIR/LIR and after GnRHa treatment. Protein-coding genes upregulated after GnRHa treatment are framed in red. Protein interaction network is predicted using STRING [Szklarczyk et al., 2015] with a confidence cut-off of 0.7. Lineweight represents strength of data support between predicted interactions.

These direct and indirect interactions between proteins encoded by differentially expressed genes are consistent with a coordinated reprogramming of gene expression induced by GnRHa treatment, and they provide an explanation for the observed changes in a large number of genes in different gene families. We note that the nitric oxide synthase- 1 gene plays a modulatory role in the biology of a variety of neuroendocrine tissues, with an important role in the regulation of testosterone release [Wang et al., 2002]. 


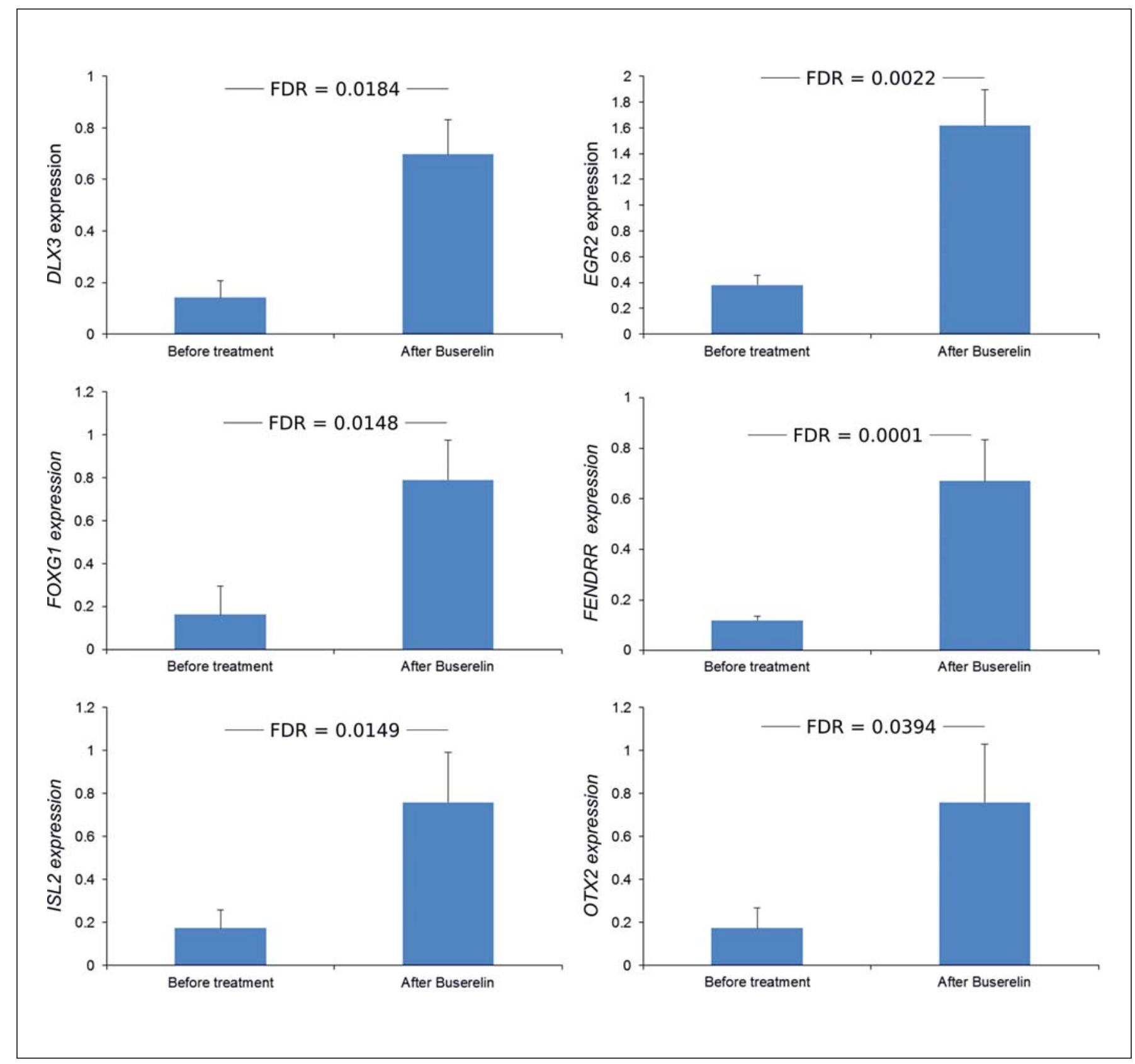

Fig. 4. Expression levels of DLX3, EGR2, FOXG1, FENDRR, ISL2, and OTX2 analyzed by RNA sequencing in cryptorchid testes lacking Ad spermatogonia before and after GnRHa/Buserelin treatment. Gene expression is shown as median RPKM values; mean absolute deviations and FDR values are presented.

\section{Discussion}

Transcriptome Analysis of Complex Human Tissues RNA profiling revealed that GnRHa treatment induces a transcriptional response involving genes which control the HPG axis, reproduction, and testosterone synthe- sis via both the classical and alternate pathways. Furthermore, our analysis showed that several lncRNAs involved in epigenetic programing are responsive to GnRHa. In contrast, surgery alone had no effect on gene expression, underscoring the importance of GnRHa treatment in rescuing fertility. 
Expression studies of human testis are inherently complicated, because a male gonad is a complex mixture of, among others, germ cells at different stages of meiotic development and nurse cells that provide hormonal and nutritional cues critical for the establishment of normal spermatogenesis. These difficulties notwithstanding, we and others have provided ample evidence that testicular expression profiles are informative [Hadziselimovic et al., 2009, 2016; Chalmel et al., 2012]. A critical issue, especially when working with human samples, is the number of cases that are included in a given analysis. First, the number of replicates affects the statistical confidence lev$\mathrm{el}$, and second, human tissue samples show intrinsic variability that needs to be controlled for. In this exploratory RNA profiling study, we have included 7 patients taken sequentially from a large ongoing study that is based on randomized patient samples. That is to say, their inclusion in the cohorts to be treated or to remain untreated was completely unbiased by any parameter other than undescended testes which were surgically corrected. Four samples from GnRHa-treated patient were compared to 3 samples from untreated controls. This sample size, while small, is sufficient for an initial transcriptome study as we present it here.

The Differential RNA Profiles of HIR/LIR versus

GnRHa-Treated/Untreated Testicular Biopsies

Partially Overlap

We found that genes unaffected in HIR patients but important for pituitary development were also upregulated after treatment (online suppl. Table 1). One factor that plays a crucial role in neural precursor cell proliferation and maintenance is SOX2 (SRY-Box 2) [Graham et al., 2003]. In rat, PROP1 (Prophet of PIT1) is consistently expressed in SOX2-expressing stem/progenitor cells in the pituitary [Yoshida et al., 2009]. Furthermore, it was shown that $S O X 2$ is able to modulate PROP1 expression and that various transcription factors might participate in the regulation of PROP1 in a SOX2-dependent or independent manner. $P R O P 1$ is a pituitary-specific transcription factor that plays an important role in pituitary organogenesis and in the differentiation of hormone-producing cells [Nishimura et al., 2016]. In this context, it is intriguing that both SOX2 and PROP1 gene expression was elevated after GnRHa treatment (online suppl. Table 1). SOX2 is also linked to the PR domain containing proteins PRDM14 and PRDM16. PRDM family proteins interact with the Notch-Hes pathway during neurogenesis and may control both nervous system patterning and the modulation of neuronal progenitor cell proliferation and differentiation
[Kinameri et al., 2008]. Given the 4 upregulated $P R D M$ genes (PRDM7/9/12/16), a provocative potential link between Prdm14 function and Prdm16 is that Prdm14 mediates the acquisition of germ cell pluripotency, in part by upregulating Sox2 [Yamaji et al., 2008]. PRDM factors act either as direct histone methyltransferases or recruit a suite of histone-modifying enzymes to target promoters and modify histone function [Hohenauer and Moore, 2012]. The absence of GnRHa stimulation of EGR1 and EGR4 remains an enigma. These (potentially) epigenetically downregulated genes appear not to be responsive to GnRHa treatment at the level of mRNA. Nevertheless, the observed LH increase after 6 months of therapy [Hadziselimovic et al., 1984] would suggest that LH secretion is the result of alternate pathway stimulation via EGR2 and EGR3, together with PROP1 (Fig. 4). Furthermore, the TAC1 gene, implicated in the control of the GnRH pulse generator and thus LH secretion, plays a critical role in the neuroendocrine regulation of reproduction, mediating its biological effects via $3 \mathrm{G}$-protein-coupled receptors [Lasaga and Debeljuk, 2011; Kalil et al., 2016]. The observed increases in TAC1 and TAC3 gene expression following GnRHa treatment indicates that both their protein products, together with the EGRs, PROK2, PROP1, LEP, and PITX1, may participate in orchestrating LH secretion (online suppl. Table 1).

\section{Are $\ln c R N A s$ Critical for the Curative Effect Observed after GnRHa Treatment?}

Our preliminary data indicate that GnRHa treatment affects the levels of numerous lncRNAs including some that are likely to be biologically relevant for human reproduction. For example, the antisense lncRNA OTX2AS1, which reacts positively to GnRHa stimulation, is interesting. While no role has been found for it, deletion of its sense gene OTX1 was found in 6 subjects with genitourinary defects. Three of these individuals were diagnosed with cryptorchidism [Jorgez et al., 2014]. Moreover, Otx2 heterozygous male mice display compromised fertility (reduced LH levels and testicular weight) due to a defect in the development, number, and migration of GnRH neurons [Larder et al., 2013]. Otx1 and Otx2 have functional similarity and interchangeable roles [Acampotra et al., 1999], and Otx2 could compensate for Otx 1 deficiency in levels that vary among subjects. Any potential roles for lncRNAs in GnRHa treatment effect remain speculative for the moment, but our results clearly indicate that they are potentially important targets for further analyses.
134

Sex Dev 2017;11:126-136 DOI: $10.1159 / 000471937$
Hadziselimovic et al. 


\section{Conclusion and Outlook}

GnRHa treatment stimulates the expression of genes involved in pituitary development and differentiation as well as neuronal development and loci involved in the canonical and alternative testosterone synthesis pathways. Critically, we now show for the first time that lncRNAs involved in the epigenetic control of gene expression are also upregulated after treatment. This finding is consistent with the idea that hypogonadotropic hypogonadism in the HIR group of cryptorchid boys might be epigenetically programmed. Our results provide initial insight into the molecular events that underlie GnRHa-mediated germline development and postnatal male gonad maturation in HIR patients. These data, while preliminary, are consistent with previous histological and clinical observations of GnRHa treatment. More work is needed to unravel the molecular mechanisms behind cryptorchidismrelated adult infertility.

\section{Acknowledgments}

This study was supported in part by the European Social Fund under the Global Grant measure. Work in the Stadler group is supported by funding from the MetastasiX project of SystemsX.ch. We thank Manuel Kohler, Department of Biosystems Science and Engineering (D-BSSE), ETH Zurich, for technical assistance with RNA sequencing.

\section{Statement of Ethics}

In accordance with the Declaration of Helsinki, the Institutional Review Board and the Independent Ethics Committee of Vilnius University approved all aspects of this study. Approval was also provided for research involving the use of material (data records or biopsy specimens) that had been collected for non-research purposes (Vilnius Regional Biomedical Research Ethics Committee, No. 158200-580-PPI-17).

\section{Disclosure Statement}

The authors have no conflicts of interest to disclose.

\section{References}

Acampora D, Avantaggiato V, Tuorto F, Barone P, Perera $M$, et al: Differential transcriptional control as the major molecular event in generating $O t x 1^{-/-}$and Otx $2^{-/-}$divergent phenotypes. Development 126:1417-1426 (1999).

Alfano G, Vitiello C, Caccioppoli C, Caramico T, Carola A, et al: Natural antisense transcripts associated with genes involved in eye development. Hum Mol Genet 14:913-923 (2005).

Benjamini Y, Hochberg Y: Controlling for false discovery rate: a practical and powerful approach to multiple testing. J R Stat Soc B 57: 289-300 (1995).

Bica DT, Hadziselimovic F: Buserelin treatment of cryptorchidism: a randomized, double-blind, placebo-controlled study. J Urol 148:617-621 (1992).

Bilius V, Verkauskas G, Dasevicius D, Kazlauskas V, Malcius D, Hadziselimovic F: Incidence of high infertility risk among unilateral cryptorchid boys. Urol Int 95:142-145 (2015).

Bond AM, Vangompel MJ, Sametsky EA, Clark MF, Savage JC, et al: Balanced gene regulation by an embryonic brain ncRNA is critical for adult hippocampal GABA circuitry. Nat Neurosci 12:1020-1027 (2009).

Chalmel F, Lardenois A, Evrard B, Mathieu R, Feig $\mathrm{C}$, et al: Global human tissue profiling and protein network analysis reveals distinct levels of transcriptional germline-specificity and identifies target genes for male infertility. Hum Reprod 27:3233-3248 (2012).

Dahl E, Koseki H, Balling R: Pax genes and organogenesis. Bioessays 19:755-765 (1997).

GnRHa Affects Genes Involved in Fertility
Dey BK, Mueller AC, Dutta A: Long non-coding RNAs as emerging regulators of differentiation, development, and disease. Transcription 5:e944014 (2014).

Diaczok D, DiVall S, Matsuo I, Wondisford FE, Wolfe AM, Radovick S: Deletion of Otx2 in GnRH neurons results in a mouse model of hypogonadotropic hypogonadism. Mol Endocrinol 25:833-846 (2011).

Duggan CD, DeMaria S, Baudhuin A, Stafford D Ngai J: Foxg1 is required for development of the vertebrate olfactory system. J Neurosci 28 5229-5239 (2008).

Forest MG, Sizonenko PC, Cathiard AM, Bertrand $\mathrm{J}$ : Hypophyso-gonadal function in humans during the first year of life. Evidence for testicular activity in early infancy. J Clin Invest 53 819-828 (1974).

Garaffo G, Conte D, Provero P, Tomaiuolo D, Luo Z, et al: The Dlx 5 and Foxg 1 transcription factors, linked via miRNA-9 and -200, are required for the development of the olfactory and GnRH system. Mol Cell Neurosci 68:103119 (2015)

Gendrel D, Job JC, Roger M: Reduced post-natal rise of testosterone in plasma of cryptorchid infants. Acta Endocrinol (Copenh) 89:372378 (1978)

Goulding MD, Lumsden A, Gruss P: Signals from the notochord and floor plate regulate the region-specific expression of two Pax genes in the developing spinal cord. Development 117: 1001-1016 (1993).

Graham V, Khudyakov J, Ellis P, Pevny L: SOX2 functions to maintain neural progenitor identity. Neuron 39:749-765 (2003).
Grote P, Herrmann BG: The long non-coding RNA Fendrr links epigenetic control mechanisms to gene regulatory networks in mammalian embryogenesis. RNA Biol 10:1579-1585 (2013).

Grote P, Wittler L, Hendrix D, Koch F, Währisch $S$, et al: The tissue-specific lncRNA Fendrr is an essential regulator of heart and body wall development in the mouse. Dev Cell 24:206-214 (2013).

Gupta R, Shah N, Wang KC, Kim J, Horlings HM, et al: Long non-coding RNA HOTAIR reprograms chromatin state to promote cancer metastasis. Nature 464:1071-1076 (2010).

Hadziselimovic F: Successful treatment of unilateral cryptorchid boys risking infertility with LH-RH analogue. International Braz J Urol 34: 319-326 (2008)

Hadziselimovic F, Herzog B: Treatment with a luteinizing hormone-releasing hormone analogue after successful orchiopexy markedly improves the chance of fertility later in life. J Urol 158:1193-1195 (1997).

Hadziselimovic F, Herzog B: The importance of both an early orchidopexy and germ cell maturation for fertility. Lancet 358:1156-1157 (2001).

Hadziselimovic F, Hoecht B: Testicular histology related to fertility outcome and postpubertal hormone status in cryptorchidism. Klinische Padiatrie 220:302-307 (2008).

Hadziselimovic F, Hoecht B, Herzog B, Girard J: Does long term treatment with Buserelin improve the fertility chances of cryptorchid testes? in Labrie F, Belanger A, Dupont A (eds): LH-RH and Its Analogues, pp 488-503 (Elsevier, Amsterdam 1984). 
Hadziselimovic F, Huff D, Duckett J, Herzog B, Elder J, et al: Treatment of cryptorchidism with low doses of buserelin over a 6-months period. Eur J Pediatr 146:S56-S58 (1987).

Hadziselimovic F, Zivkovic D, Bica DTG, Emmons LR: The importance of mini-puberty for fertility in cryptorchidism. J Urol 174:1536-15391539 (2005).

Hadziselimovic F, Hadziselimovic NO, Demougin P, Krey G, Hoecht B, Oakeley EJ: EGR4 is a master gene responsible for fertility in cryptorchidism. Sex Dev 3:253-263 (2009).

Hadziselimovic F, Hadziselimovic NO, Demougin P, Oakeley EJ: Testicular gene expression in cryptorchid boys at risk of azoospermia. Sex Dev 5:49-59 (2011).

Hadziselimovic F, Gegenschatz-Schmid K, Verkauskas G, Docampo-Garcia MJ, Demougin P, et al: Gene expression changes underlying idiopathic central hypogonadism in cryptorchidism with defective mini-puberty. Sex Dev 10: 136-146 (2016).

Hedinger C: Histopathology of the cryptorchid testis, in Bierich JR, Giarola A (eds): Proceedings of the Serono Symposia, Vol 25, pp 29-38 (Academic Press, London 1979).

Hohenauer T, Moore A: The Prdm family: expanding roles in stem cells and development. Development 139:2267-2282 (2012).

Jorgez CJ, Rosenfeld JA, Wilken NR, Vangapandu HV, Sahin A, et al: Genitourinary defects associated with genomic deletions in $2 \mathrm{p} 15$ encompassing OTX1. PLoS One 9:e107028 (2014).

Jostes B, Walther C, Gruss P: The murine paired box gene, $P a x 7$, is expressed specifically during the development of the nervous and muscular system. Mech Dev 33:27-37(1990).

Kalil B, Ramaswamy S, Plant TM: The distribution of substance $P$ and kisspeptin in the mediobasal hypothalamus of the male rhesus monkey and a comparison of intravenous administration of these peptides to release GnRH as reflected by LH secretion. Neuroendocrinology 103:711-723 (2016).

Kinameri E, Inoue T, Aruga J, Imayoshi I, Kageyama R, et al: Prdm proto-oncogene transcription factor family expression and interaction with the Notch-Hes pathway in mouse neurogenesis. PLoS One 3:e3859 (2008).

Kioussi C, O'Connell S, St-Onge L, Treier M, Gleiberman S: Pax6 is essential for establishing ventral-dorsal cell boundaries in pituitary gland development. Proc Natl Acad Sci USA 96:14378-14382 (1999).

Kolon TF, Herndon CDA, Baker LA, Baskin LS, Baxter CG, et al: Evaluation and treatment of cryptorchidism: AUA guideline. J Urol 192: 337-345 (2014).

Larder R, Kimura I, Meadows J, Clark DD, Mayo S, Mellon PL: Gene dosage of Otx2 is important for fertility in male mice. Mol Cell Endocrinol 377:16-22 (2013).
Lasaga M, Debeljuk L: Tachykinins and the hypothalamo-pituitary-gonadal axis: an update. Peptides 32:1972-1978 (2011).

Loos F, Maduro C, Loda A, Lehmann J, Kremers GJ, et al: Xist and Tsix transcription dynamics is regulated by the X-to-autosome ratio and semi-stable transcriptional states. Mol Cell Biol 36:2656-2667 (2016).

Lund SP, Nettleton D, McCarthy D, Smyth GK: Detecting differential expression in RNAsequence data using quasi-likelihood with shrunken dispersion estimates. Stat Appl Genet Mol Biol DOI: 10.1515/1544-6115.1826 (2012).

Nagano T, Mitchell JA, Sanz LA, Pauler FM, Ferguson-Smith AC, et al: The Air noncoding RNA epigenetically silences transcription by targeting G9a to chromatin. Science 322:17171720 (2008).

Nini L, Zhang JH, Pandey M, Panicker LM, Simonds WF: Expression of the G $\beta 5 / R 7-R G S$ protein complex in pituitary and pancreatic islet cells. Endocrine 42:214-217 (2012).

Nishimura N, Ueharu H, Nishihara H, Shibuya S, Yoshida S, et al:. Search for regulatory factors of the pituitary-specific transcription factor PROP1 gene. J Reprod Dev 62:93-102 (2016).

Park JI, Park HJ, Lee YI, Seo YM, Chun SY: Regulation of NGFI-B expression during the ovulatory process. Mol Cell Endocrinol 202:25-29 (2003).

Pi M, Quarles LD: Novel bone endocrine networks integrating mineral and energy metabolism. Curr Osteoporos Rep 11:391-399 (2013).

Pi M, Parrill AL, Quarles LD: GPRC6A mediates the non-genomic effects of steroids. J Biol Chem 285 39953-39964 (2010).

Rinn JL, Kertesz M, Wang JK, Squazzo SL, Xu X, et al: Functional demarcation of active and silent chromatin domains in human HOX loci by noncoding RNAS. Cell 129:1311-1323 (2007).

Ritzén ME, Bergh A, Bjerknes R, Christiansen P, Cortes D, et al: Nordic consensus on treatment of undescended testes. Acta Paediatr 96:638643 (2007)

Robinson MD, McCarthy DJ, Smyth GK: edgeR: a Bioconductor package for differential expression analysis of digital gene expression data Bioinformatics 26:139-140 (2010).

Seguchi H, Hadziselimovic F: Ultramicroscopic studies on the seminiferous tubule in children from birth to puberty. I. Spermatogonia development. Verh Anat Ges 30:364-366 (1974).

Stricker SH, Steenpass L, Pauler FM, Santoro F, Latos PA, et al: Silencing and transcriptional properties of the imprinted Airn ncRNA are independent of the endogenous promoter. EMBO J 27:3116-3128 (2008).

Szklarczyk D, Franceschini A, Wyder S, Forslund $\mathrm{K}$, Heller D, et al: STRING v10: protein-protein interaction networks, integrated over the tree of life. Nucleic Acids Res 43:D447-D452 (2015).
Teerds KJ, Huhtaniemi IT: Morphological and functional maturation of Leydig cells: from rodent models to primates. Hum Reprod Update 21:310-328 (2015).

Urakawa I, Yamazaki Y, Shimada T, Iijima K, Hasegawa $\mathrm{H}$, et al: Klotho converts canonical FGF receptor into a specific receptor for FGF23. Nature 444:770-774 (2006).

Verkauskas G, Malcius D, Eidukaite A, Vilimas J, Dasevicius D: Prospective study of histological and endocrine parameters of gonadal function in boys with cryptorchidism. J Pediatr Urol 12: 238.e1-6 (2016).

von Elm E, Altman DG, Egger M, Pocock SI, Gøtzsche PC, Vandenbroucke JP: The strengthening the reporting of observational studies in epidemiology (STROBE) statement: guidelines for reporting observational studies. Int J Surg 12:1495-1499 (2014).

Walther C, Gruss P: Pax-6, a murine paired box gene, is expressed in the developing CNS. Development 113:1435-1449 (1991).

Wang Y, Newton DC, Miller TL, Teichert AM, Phillips MJ, et al: An alternative promoter of the human neuronal nitric oxide synthase gene is expressed specifically in Leydig cells. Am J Pathol 160:369-380 (2002).

Weber S, Salabei JK, Möller G, Kremmer E, Bhatnagar A: Aldo-keto Reductase 1B15 (AKR1B15): a mitochondrial human aldo-keto reductase with activity toward steroids and 3-keto-acyl-CoA conjugates. J Biol Chem 290: 6531-6545 (2015).

Werner A, Carlile M, Swan D: What do natural antisense transcripts regulate? RNA Biol 6:4348 (2009).

Winter JSD, Hughes IA, Reyes FI, Faiman C: Pituitary gonadal relations in infancy: II. Patterns of serum gonadal steroid concentrations in man from birth to two years of age. J Clin Endocrinol Metab 42:679-686 (1976).

Xie H, Cherrington BD, Meadows JD, Witham E, Mellon PL: Msx1 homeodomain protein represses the aGSU and GnRH receptor genes during gonadotrope development. Mol Endocrinol 27:422-436 (2013).

Yamaji M, Seki Y, Kurimoto K, Yabuta Y, Yuasa M, et al: Critical function of Prdm14 for the establishment of the germ cell lineage in mice. Nature Genet 40:1016-1022 (2008).

Yoshida S, Kato T, Susa T, Cai LY, Nakayama M, Kato Y: PROP1 coexists with SOX2 and induces PIT1-commitment cells. Biochem Biophys Res Commun 385:11-15 (2009).

Zhang J, Zhang P, Wang L, Piao HL, Ma L: Long non-coding RNA HOTAIR in carcinogenesis and metastasis. Acta Biochim Biophy Sin 46: 1-5 (2014)

Zivkovic D, Bica DT, Hadziselimovic F: Relationship between adult dark spermatogonia and secretory capacity of Leydig cells in cryptorchidism. BJU Int 100:1147-1149 (2007). 